\title{
A NOTE ON THE TEXT AND THE TRANSLATION
}

The edition used for this translation is a recent Hong Kong reprint. I have compared it with a 1949 Shanghai edition lent to me by the Hoover Institute at Stanford University. The two editions are, to the best of my knowledge, identical.

Those who have read Evan King's translation published in 1945 as Rickshaw Boy will wonder if Rickshaw is the same novel. It is. King cut, rearranged, rewrote, invented characters, and changed the ending. The girl student and One Pock Li are King's, not Lao She's. King also added considerable embellishment to the two seduction scenes.

This new translation omits nothing and alters nothing. Some small additions to the text have been made whenever necessary to clarify terms and allusions which the non-Chinese reader will not understand. This method is the least obstructive to the flow of the narrative and does supply the supplementary material necessary for clarity of meaning.

Lao She wrote eloquently rather than elegantly. He used the dialect of Peking, which was famous for its liveliness and colorful idioms. I am, of course, solely responsible for errors but I have done what I can to convey his style and his strength. 